\title{
DISCRIMINATION AND SUBJECTIVE WELL-BEING: PROTECTIVE INFLUENCES OF MEMBERSHIP IN A DISCRIMINATED CATEGORY
}

\author{
Karel Hnilica \\ Department of Cultural Studies, Faculty of Philosophy, Charles University, Prague, Czech Republic
}

\begin{abstract}
SUMMARY
Background: Research reveals that discrimination has harmful effects on health and quality of life. Among the most frequent types of discrimination pertains gender and age discrimination. Research results show that discriminatory behaviours based on gender afflict predominantly women; age discrimination afflicts mainly older adults. At the same time, it has been found that members of these traditionally discriminated categories often use strategies that mitigate the effects of discrimination.

Hypotheses: Discrimination will have detrimental effects on subjective well-being. But its effects will be most harmful for persons who are not members of the traditionally discriminated categories.

Methods: These hypotheses were tested on data from three waves of the European Social Survey that the Czech Republic also participated in. Data were analyzed in a series of multilevel random coefficients regression analyses with respondents nested within states and states nested within years of study.

Results: Both perceived gender discrimination and perceived age discrimination have negative effects on subjective well-being. However, gender discrimination had more harmful effects on the subjective well-being of men than women and age discrimination had the most harmful effects on the subjective well-being of people in their middle ages, not the elderly ones.

Conclusion: Discrimination does not need to have most harmful effects on the quality of life of members of the categories that are discriminated against most often.
\end{abstract}

Key words: gender discrimination, age discrimination, subjective well-being, social category

Address for correspondence: K. Hnilica, Department of Cultural Studies, Faculty of Philosophy, Celetná 20, Prague 1, 110 00, Czech Republic. E-mail: khnilica@gmail.com

\section{INTRODUCTION}

Research results show that discrimination, i. e. disadvantaging individuals on the basis of their membership in some social category or group, has negative influences on health and quality of life (1-11). For example, Williams and his colleagues (11) have analyzed 53 primary studies. In most of these studies a detrimental effects of discrimination on physical as well as subjective health perception and on indicators of life quality, such as anxiety, depression, psychological stress, happiness and satisfaction with life, were reported. According to these authors, the most common types of discrimination are based on race/ethnicity, gender, age, and appearance.

At the same time, some authors show that members of the discriminated categories may use strategies which mitigate the influences of discrimination (12-18), among them strategies based on self-categorization. Members of a discriminated category may take advantage of the fact that their category is known to be discriminated against. They may attribute their personal failures to discrimination, not to their own activities and qualities, compare themselves with other members of their category and avoid comparison with members of more successful categories, choose for inter-group comparisons only some dimensions, etc. (12, 13). Membership in a discriminated category thus may facilitate adaptation to discrimination (21).

\section{Hypotheses}

The results of the aforementioned studies led to assumption that discrimination has harmful effects on the quality of life of persons discriminated against, and at the same time, that it has more harmful influences on the quality of life of persons, who are not members of the traditionally discriminated categories. These persons do not expect themselves to be discriminated against, cannot attribute discrimination to social-structural factors, and have at their disposal a more restricted repertoire of strategies for coping with discrimination.

This study pays attention to two forms of discrimination: gender discrimination (sexism) and age discrimination (ageism). The first one is associated predominantly with females and the second one is prevailing among old people.

Four hypotheses are proposed:

1. Gender discrimination have detrimental influences on subjective well-being of the persons discriminated against.

2. At the same time, gender discrimination have more deleterious influences on subjective well-being of males than females.

3. Age discrimination have detrimental influences on subjective well-being of all afflicted persons.

4. At the same time, age discrimination have more deleterious influences on subjective well-being of middle-aged adults than on subjective well-being of elderly persons. 


\section{MATERIALS AND METHODS}

These hypotheses were tested using data from three waves of the European Social Survey (ESS) which were carried out in the years 2002, 2004, and 2006.

\section{Samples}

States. The surveys were carried out in 24 European states. These were Belgium, Czech Republic, Denmark, Estonia, Finland, France, Netherlands, Ireland, Iceland, Luxemburg, Hungary, Germany, Norway, Poland, Portugal, Austria, Greece, Slovenia, Slovakia, United Kingdom, Spain, Sweden, Switzerland, and Ukraine. Seventeen states took part in all three waves, 7 states took part in only two waves (Estonia, Slovakia and Ukraine did not take part in the 2002 survey, Czech Republic, Luxemburg, and Greece did not take part in the 2006 survey). All states took part in the 2004 wave.

Respondents. Samples consist of respondents older than 15 years. In a state with population of two million or more the sample consists of at least 1,500 respondents. In a state with population less than two million the sample consists of at least 800 respondents. In total, in the three waves of ESS 123,817 respondents took part (39,552 in the year 2002, 46,331 in the year 2004, and 37,934 in the year 2006).

To reduce the discrepancies between the composition of samples and the demographic structures of populations, two types of weights were used. The so called "design weights" reduce discrepancies between sample and population in a state and the so called "population weights" adjust sample sizes in the frame of Europe. The study combined both weights so that the effective sample is representative of the population of Europe.

\section{Questionnaire}

Subjective well-being (SWB; happiness and satisfaction with life). Subjective well-being is one of the many facets of quality of life. In the database of ESS there are two items which measure subjective well-being. The first item concerns the feelings of happiness, the second one concerns satisfaction with life as a whole. In both cases the scale ranges from 0 to 10 (the higher the scale value, the higher the intensity of the variable). These two items highly intercorrelate $(\mathrm{r}=0.674)$, and were therefore combined into one scale (index of SWB).

Perceived discrimination. Discrimination was probed by the question: "Are you member of a group discriminated against in this country?" When the answer was affirmative, some questions specifying the cause of discrimination followed. Only data from respondents who said they were objects of gender or age discrimination were analyzed. This self-reported discrimination is often called 'perceived discrimination'.

Education and marital status of respondents were also analyzed. Education level was defined by the number of years of schooling. Marital status was reduced to dichotomy $(1=$ married; $0=$ other $)$.

\section{Statistical Analyses}

All analyses were run in SPSS V15.0 (MIXED MODELS, algorithm ML). The MRC RA (Multilevel Random Coefficients Regression Analysis) was used with respondents nested within states and states nested within years of study. These two last sources explained $15.5 \%$ of variance in the index of subjective well-being.

\section{RESULTS}

\section{Perceived Gender Discrimination}

Gender discrimination was reported by 703 women and 87 men. As expected, gender discrimination afflicts more often women than men.

Table 1 shows a series of MRC RA. There are three blocks of rows in the table. In the first block there are the values of partial regression coefficients (betas). The criterion is in all analyses the index of subjective well-being (happiness and satisfaction with life).

Model I includes only control variables. Inspection of the betas shows that women, younger people, more educated people and the married ones are on the average more happy and satisfied with their lives. The significant quadratic component of age $\left(\mathrm{age}^{2}\right)$ shows that the relationship between age and SWB is U-shaped.

Results of tests of the first two hypotheses are shown in model II. Firstly, it can be seen that perceived gender discrimination has a negative effect on subjective well-being. The partial regression coefficient is statistically significant $\left(\mathrm{B}_{\mathrm{PGD}}=-0.644\right.$; $\left.\mathrm{p}<0.001\right)$. In accordance with the second hypothesis gender discrimination has more harmful effects on the subjective well-being of men rather than women - the interaction of gender with perceived gender discrimination is statistically significant $\left(\mathrm{B}_{\text {gender } x \mathrm{PGD}}=-0.599\right.$; $\mathrm{p}<0.05)$. The form of this interaction is pictured in Fig. 1 .

Table 1. Results of the regression analyses

\begin{tabular}{|c|c|c|c|}
\hline & \multicolumn{3}{|c|}{ Models } \\
\hline & I & ॥ & III \\
\hline Gender & $-0.038^{* *}$ & $-0.043^{\star *}$ & $-0.037^{\star *}$ \\
\hline Age & $-0.016^{* *}$ & $-0.016^{* *}$ & $-0.016^{* *}$ \\
\hline $\mathrm{Age}^{2}$ & $0.001^{* *}$ & $0.001^{* *}$ & $0.001^{* *}$ \\
\hline Education & $0.055^{* *}$ & $0.056^{* *}$ & $0.055^{\star *}$ \\
\hline Marital status & $0.803^{* *}$ & $0.801^{* *}$ & $0.798^{* *}$ \\
\hline Gender discrimination (PGD) & & $-0.644^{* *}$ & \\
\hline Gender x PGD & & $-0.599^{*}$ & \\
\hline Age discrimination (PAD) & & & $-1.446^{* *}$ \\
\hline Age x PAD & & & -0.001 \\
\hline $\mathrm{Age}^{2} \times \mathrm{PAD}$ & & & $0.001^{* *}$ \\
\hline$\sigma^{2}$ & $3.455^{* *}$ & $3.452^{* *}$ & $3.447^{* *}$ \\
\hline$T_{00}$ & $0.480^{* *}$ & $0.481^{* *}$ & $0.479^{* *}$ \\
\hline$-2 \mathrm{LL}$ & 280,139 & 280,073 & 279,983 \\
\hline df & 8 & 10 & 11 \\
\hline \multicolumn{4}{|c|}{$\begin{array}{l}{ }^{*} p<0.05 ;{ }^{* *} p<0.01 \\
\text { PGD - perceived gender discrimination } \\
\text { PAD - perceived age discrimination } \\
\text { codes for dummy variables: } \\
\text { gender: } 0=\text { female, } 1=\text { male } \\
\text { marital status: } 1=\text { married, } 0=\text { other } \\
\text { discrimination (PGD/PAD): } 0=\text { no, } 1=\text { yes }\end{array}$} \\
\hline
\end{tabular}


The second block of Table 1 gives information about variances. The first row in this block informs about the value of residual variance $\left(\sigma^{2}\right)$. The residual variance is highly significant. The second row in this block gives the variances of intercepts $\left(\tau_{00}\right)$. It shows that there are highly significant differences in average SWB of the states.

The third block of Table 1 gives values of the information criterion -2LL (-2 Log Likelihood; commas here separate thousands, not decimals) and the appropriate number of degrees of freedom

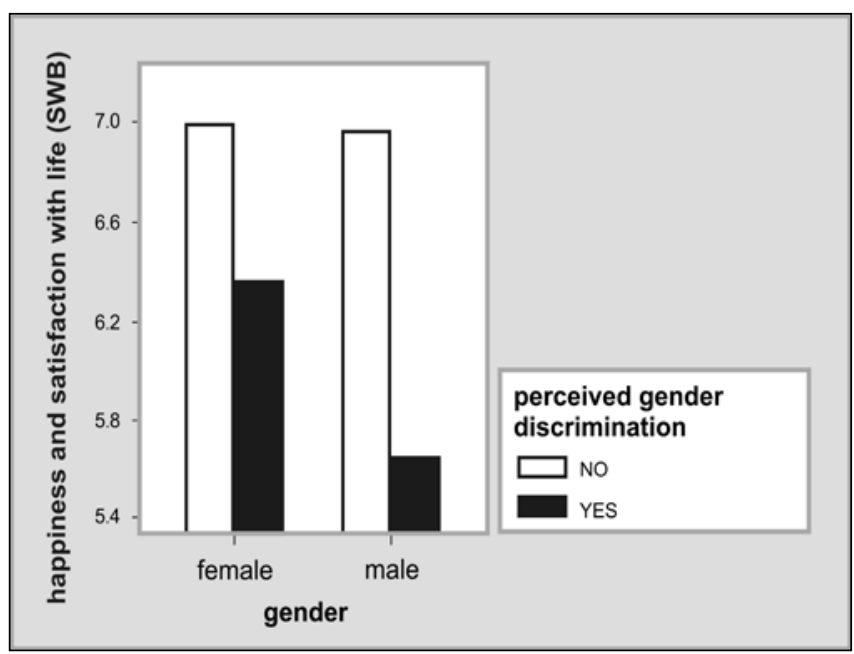

Fig. 1. Effects of perceived gender discrimination.

(df). The comparison shows, that second model fits the data much better than the first one: $\chi_{(2)}^{2}=66 ; \mathrm{p}<0.001$.

\section{Perceived Age Discrimination}

Young people in the range of 15 to 39 years of age reported age discrimination in $0.44 \%$ of cases, middle-aged people (from 40 to 64 years of age) in $0.59 \%$ of cases, and old people (older than 65 years) in $1.08 \%$ of cases. As expected, age discrimination does not afflict all age categories equally often.

The results of the tests of the 3rd and 4th hypotheses are shown in the model III of Table 1. Firstly, these results show that age discrimination has harmful effects on subjective well-being. Respondents of all ages, who hold themselves to be discriminated against due to their age, are on the average less happy and less satisfied with their lives than respondents, who do not feel to be discriminated. The difference between these two groups is statistically significant $\left(\mathrm{B}_{\mathrm{PAD}}=-1.444 ; \mathrm{p}<0.001\right)$. Interaction of the linear component of age with perceived age discrimination is not significant $\left(\mathrm{B}_{\text {age } X A D}=-0.001 ; \mathrm{ns}\right.$.). It means that the average difference between the persons who perceive themselves to be age-discriminated and the rest does not change with age.

But the interaction of perceived age discrimination with the quadratic component of age is significant $\left(\mathrm{B}_{\text {age } 2 \times \mathrm{PAD}}=0.001\right.$; $\mathrm{p}<0.001)$. The form of this interaction is pictured in the Fig. 2 . Figure 2 shows that age discrimination has the most harmful effects on subjective well-being of people in their middle ages, not the elderly ones. The two curves have different points of minima. For people who do not consider themselves to be age discriminated reaches the curvature the minimum at about their seventieth year of age and then slowly runs upwards. For people who do hold themselves to be age discriminated reaches the curvature the minimum at about their fifty-fifth year of age and then runs steeply upwards.



Fig. 2. Effects of perceived age discrimination.

Comparison of the first model with the third one shows that the third model fits the data significantly better than the first model: $\chi_{(3)}^{2}=155 ; \mathrm{p}<0.001$.

\section{DISCUSSION}

The results show that the membership in a traditionally discriminated category may have protective effects on subjective well-being. From Fig. 1 it can be seen that members of both sexes who do not perceive themselves to be discriminated on the base of gender have nearly equal subjective well-being (the difference of 0.04 point on the eleven-point scale is negligible). At the same time, it is clear that gender discrimination do have harmful effects on subjective well-being. In addition, the findings also reveal that men, who think they are discriminated against due to the fact that they are men, have significantly worse subjective well-being perception than women who think they are discriminated against for the sake of being women.

Results for age discrimination are similar. The relationship between age and subjective well-being is generally U-shaped. But in comparison with persons who do not hold themselves to be age-discriminated the curve for persons who do perceive themselves to be age-discriminated is set lower, is more pronouncedly U-shaped, and reaches the minimum in the persons' middle ages, not in their old ages.

Results of the aforementioned analyses are therefore consistent with results of many other researches showing that discrimination has deleterious influences on health and life quality (1-11). At the same time these results show that these effects do not need to have the most deleterious effects on subjective well-being of members of categories that are discriminated against the most often. 
In conclusion, a few words concerning the problems of measurement and direction of causal influence should be noted. In population-based studies that are not specifically oriented on the study of discrimination, the discrimination is usually measured by a single question. Of course, the validity and reliability of the results would be more psychometrically sound if there were used some multi-item questionnaires (19-20).

The second question concerns the causal direction. On the basis of cross-sectional data we cannot exclude the possibility that quality of life has influences on the self-reporting of discrimination. For example Kessler et al. (8) suggest the possibility that depressive persons perceive and report discrimination more often than nondepressive persons (over-reporting). We could add hypothesis that happy persons perceive and report discrimination less often than unhappy persons (under-reporting) (22). But it is important to realize that these back influences have affect on estimates of the main effects, not interactions. These back influences therefore cannot explain the protective influences the membership in a discriminated against category has on subjective well-being. In other words, they explain neither why gender discrimination has more harmful affects on the subjective well-being of men than women, nor why age discrimination has more harmful affects on the subjective well-being of persons in their middle ages than of the elderly.

\section{REFERENCES}

1. Arber S, Cooper H. Gender differences in health in later life: the new paradox? Soc Sci Med. 1999 Jan;48(1):61-76.

2. Borrell LN, Kiefe CI, Williams DR, Diez-Roux AV, Gordon-Larsen P. Self-reported health, perceived racial discrimination, and skin color in African Americans in the CARDIA study. Soc Sci Med. 2006 Sep;63(6):1415-27.

3. Brown TN, Williams DR, Jackson JS, Neighbors HW, Torres M, Sellers SL, et al. "Being Black and feeling blue": the mental health consequences of racial discrimination. Race Soc. 2000 Apr;2(2):117-31.

4. Dambrun M. Gender differences in mental health: the mediating role of perceived personal discrimination. J Appl Soc Psychol. 2007 May;37(5):1118-29.

5. Gee GC. A multilevel analysis of the relationship between institutional and individual racial discrimination and health status. Am J Public Health. 2002 Apr;92(4):615-23.

6. Gee GC, Spencer MS, Chen J, Takeuchi D. A nationwide study of discrimination and chronic health conditions among Asian Americans. Am J Public Health. 2007 Jul;97(7):1275-82.
7. Harris R, Tobias M, Jeffreys M, Waldegrave K, Karlsen S, Nazroo J. Effects of self-reported racial discrimination and deprivation on Māori health and inequalities in New Zealand: cross-sectional study. Lancet. 2006 Jun 17;367(9527):2005-9.

8. Kessler RC, Mickelson KD, Williams DR. The prevalence, distribution, and mental health correlates of perceived discrimination in the United States. J Health Soc Behav. 1999 Sep;40(3):208-30.

9. Noh S, Beiser M, Kaspar V, Hou F, Rummens J. Perceived racial discrimination, depression, and coping: a study of Southeast Asian refugees in Canada. J Health Soc Behav. 1999 Sep;40(3):193-207.

10. Williams DR. Racial/ethnic variations in women's health: the social embeddedness of health. Am J Public Health. 2002 Apr;92(4):588-97.

11. Williams DR, Neighbors HW, Jackson JS. Racial/ethnic discrimination and health: findings from community studies. Am J Public Health. 2003 Feb;93(2):200-8.

12. Branscombe NR, Schmitt MT, Harvey RD. Perceiving pervasive discrimination among African Americans: implications for group identification and well-being. J Pers Social Psychol. 1999 Jul;77(1):135-49.

13. Crocker J, Major B. Social stigma and self-esteem: the self-protective properties of stigma. Psychol Rev. 1989 Jul;96(4):608-30.

14. Dion KL, Dion KK, Pak AW. Personality-based hardiness as a buffer for discrimination-related stress in members of Toronto's Chinese community. Can J Behav Sci. 1992 Oct;24(4): 517-36.

15. Foster MD, Dion KL. Dispositional hardiness and women's well-being relating to gender discrimination: the role of minimization. Psychol Women Q. 2003 Jul;27(3):197-208.

16. Lindström M. Social capital, anticipated ethnic discrimination and selfreported psychological health: a population-based study. Soc Sci Med. 2008 Jan;66(1):1-13.

17. Mossakowski KN. Coping with perceived discrimination: does ethnic identity protect mental health? J Health Soc Behav. 2003 Sep;44(3):31831.

18. You CH, Lee RM. Does ethnic identity buffer or exacerbate the effects of frequent racial discrimination on situational well-being of Asian American? J Couns Psychol. 2008 Jan; 55(1):63-74.

19. Krieger N, Smith K, Naishadham D, Hartman C, Barbeau EM. Experiences of discrimination: validity and reliability of a self-report measure for population health research on racism and health. Soc Sci Med. 2005 Oct;61(7):1576-96.

20. Landrine H, Klonoff EA, Corral I, Fernandez S, Roesch S. Conceptualizing and measuring ethnic discrimination in health research. J Behav Med. 2006 Feb;29(1):79-94.

21. Hnilica K. Diagnosis and age moderate the relationship among health, emotional life, and life satisfaction. Čs Psychol. 2006 Dec;50(6):489-507. (In Czech.)

22. Hnilica K. Reciprocal influences of the quality of life. Čs Psychol. 2009 May;53(3):224-40. (In Czech.)

Received February 4, 2010

Accepted in revised form November 26, 2010 